and a maximum of $48 \cdot 3^{\circ}$ on December 14, thus showing, as usual, a greatly reduced annual amplitude and almost a complete reversal of seasons at this depth. (See also p. 227.)

\section{The Treub Foundation of Buitenzorg, Java}

Dr. K. W. Dammerman, director of the Botanic Gardens, Buitenzorg, has sent us a copy of the first report of the Treub Foundation (Treub-Stichting), which was established at the end of last year for the administration and application of the Treub Fund collected in Netherlands India. When, in 1933, the Government of Netherlands India had, for reasons of economy, to make substantial reductions in the grants to the biological establishments at Buitenzorg, a committee was formed to collect donations for this Fund; and the Government gave permission for any sums received from the sale of surplus plants to be added to the Fund. The Treub Foundation has now been legally constituted to take over and administer this Fund.

THE object of the Foundation is to co-operate in maintaining, and, if possible, in extending the scope of, the scientific institutions united under the name of the 'Government Botanic Gardens', namely, the Botanic Gardens at Buitenzorg and Tjibodas, the Treub Laboratory, the Herbarium, and the Zoological Museum and Laboratory at Buitenzorg, and the Marine Investigation Laboratory at Batavia. The Foundation distinguishes donors, patrons, subscribers and corresponding members. Donors are corpora. tions which contribute one sum of at least Fl. 1,000 and persons who contribute one sum of at least Fl. 500; and patrons those who contribute one sum of at least F1. 100; subscribers contribute at least Fl. 10 annually. Persons who, because of their interest in the Government Botanic Gardens or in scientific research in the Dutch East Indies, are appointed corresponding members will not be obliged to pay any subscription, but, in their own countries, will look after the interests of the Buitenzorg Institutions in co-operation and in concert with the Foundation. The chairman of the Foundation is Mr. J. H. B. Kuneman, member of the Council of Netherlands India; the secretary is the director of the Government Botanic Gardens, and the treasurer, the president-director of the Java Bank. The capital of the Foundation amounted to about Fl. 20,000 on December 31, 1936. Sir Arthur Hill, director of the Royal Botanic Gardens, Kew, has accepted an invitation to act as a corresponding member of the Foundation in Great Britain, and Dr. David Fairchild, Prof. Elmer D. Merrill and Dr. Thomas Barbour have been appointed corresponding members in the United States.

\section{Phenology of 1936}

ThE Phenological Report for 1936, recently issued by the Royal Meteorological Society, contains the usual mass of statistics, maps, graphs, etc. of the relations between fauna, flora and the weather. It is the forty-sixth report, compiled mainly by Ivan D. Margary, from 477 reporters. The year was remark- able for its sunlessness generally, for wetness in England and Wales, and a cool winter, so that plants generally flowered late-all in the Midlands, nearly ail England, south-east, south-west, and south Ireland, but were earlier in Scotland, especially the west. Insects nearly all appeared late in England, and save for Scotland, spring migrants were generally late because of the cool April ; the autumn migrants were mostly early in moving. As in 1934, the lesser celandine was very late, but by early April vegetation had made up the lost ground; late frosts damaged potatoes, beans and most tender growths; fungi were scarce after August, although flowers were especially fine in the dry, sunny late summer and autumn; trees often remained green late, and wind, more often than frost, caused the leaf-fall. A considerable amount of second flowering was noted in autumn on elder, laburnum, dog-rose and apple. Wild fruits did not do so well as cultivated ones, where bumper crops of apples, plums and raspberries were obtained. Garden crops did good, cereals bad, and hay was ruined by rain. After a record early wave of migrants in March, the long April frost caused a marked hold-up until the sunny third week. Bird song was less in the May drought and cold early June; redwings and fieldfares were scarce in the mild winter. An increase in red squirrels was noted in south-west England; but grey squirrels hold their own in the south-east.

\section{An Extra Receiver for the Telephone}

BEFORE the introduction of the modern form of hand micro-telephone instrument and before thermionic amplifiers were introduced on trunk telephone lines, the extra receiver was considered a useful means of improving reception. In modern times the popularity of this receiver has greatly declined. At first sight it would look as if when listening with both ears to a long distance call or when in a noisy room it would be a great improvement; but this is rarely the case owing to what is called side-tone, that is, the repro. duction by the receiver of room-noise falling on the microphone at the same station. It is far more difficult to sort out the wanted from the unwanted sounds when both are entering both ears, than when one ear alone is used. In the Engineering Supplement to the Siemens Magazine of April a new type of the extra receiver is described. It is pointed out that in certain circumstances it is very useful to have an additional receiver. It enables a third person to listen to the conversation and, if necessary, make notes. As this facility is only required occasionally, and if this receiver were always left in circuit it would permanently 'degrade' the hearing, a switch actuated only when the 'watch' receiver is pressed against the ear is introduced in the circuit. Incidentally, this receiver enables the user to know when he is using sufficient pressure. It is not sufficiently recognized that in everyday use, pressing the telephone too lightly against the ear distorts sounds communicated. In the new table pattern 'neophone' telephone, the extra watch receiver is hung up by a hook. When lifted off and pressed against the user's ear, it is immediately available. 